Artigos

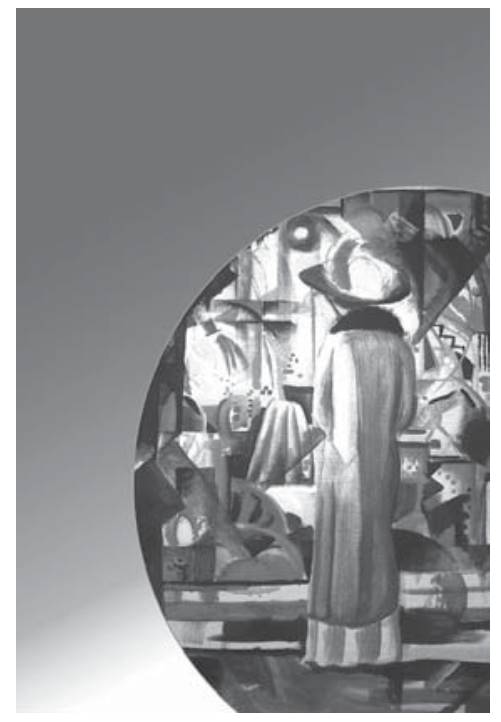




\title{
DO ESTADO-NAÇÃO AO ESPAÇO-MUNDO: AS CONDIÇÕES HISTÓRICAS DA RENOVAÇÃO DA EDUCAÇÃO COMPARÁDA*
}

\author{
RÉGIS MALET
}

\begin{abstract}
RESUMO: A educação comparada conheceu fortunas diversas ao longo de sua evolução. Após um longo período de tensões não-resolvidas e, finalmente, de ostracismo, enquanto se esforçava por satisfazer tanto as injunções de utilidade do político como as exigências teóricas e conceituais dos meios acadêmicos, esta última década conheceu um vigoroso ressurgimento da educação comparada. De fato, confrontada, hoje em dia, com novos desafios de conhecimento, aos quais deve em parte sua renovação, a educação comparada há de se recompor de acordo com mudanças culturais: o crescimento de problemáticas educativas transculturais, o enfraquecimento dos EstadosNações que acompanhou a consolidação de territórios identitários supranacionais (como a Europa) ou infranacionais (como as regiōes) e fenômenos de expansão e interdependência cultural (globalização). Tantas conversóes civilizacionais cujos desafios e sentido para a pesquisa comparativa contemporânea discutiremos aqui.
\end{abstract}

Palavras-chave: Educação comparada. Método comparatista. Educação transcultural.

FROM NATION-STATE TO THE WORLD-SPACE:

THE HISTORICAL CONDITIONS OF THE COMPARED EDUCATION RENEWAL

ABSTRACT: Abstract: Comparative education has had varying success during its evolution. After a long period of unresolved tensions and even ostracism, when toiling to satisfy both the utilitarian injunctions of the politics and the theoretical and conceptual requirements of the academic sphere, the comparative and international research in education has made a vigorous reappearance these last ten years. As a matter of fact, now faced with new knowledge chal-

* Tradução de Alain François.

** Universidade Charles de Gaulle (Lille III).E-mail: regis.malet@tiscali.fr/regis.malet@wanadoo.fr

Educ. Soc., Campinas, vol. 25, n. 89, p. 1301-1332, Set./Dez. 2004

Disponível em <http://www.cedes.unicamp.br> 
Do Estado-nação ao espaço-mundo...

lenges, to which it partly owes its revival, comparative education will have to reconstitute itself according to such cultural changes as the growth of transcultural educational problems, the weakening of the Nation States that has accompanied the strengthening of supra- or infra-national identity territories (such as Europe and the regions, respectively) and phenomena of cultural expansion and interdependency (globalization). These are the civilizational conversions whose challenges and sense are discussed here.

Key words: Compared education. Comparative method. Transcultural education.

Apresentação: rumo a uma genealogia dos comparatismos em educação

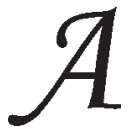

situação presente de um campo científico não tem sentido a não ser em referência a seu desenvolvimento histórico. Conseqüentemente, para medirmos os desafios com os quais a educação comparada se defronta na época atual, parece útil empreender sua arqueologia, nem que seja para reintroduzir talvez não coesão, mas pelo menos coerência e legibilidade num campo às vezes apreendido como epistemologicamente pouco fundamentado. Metodológica e teoricamente fragmentada, a comparação em educação tem evoluído consideravelmente desde os primeiros estudos que buscavam fundar uma ciência da educação comparada (Jullien de Paris, 1962) ou caracterizar os grandes princípios organizadores dos sistemas educativos nacionais (Sadler, 1979), até as perspectivas globalizantes (Ginsburg, 1991) e histórico-hermenêuticas mais recentes (Nóvoa \& Lawn, 2002).

A o longo de sua evolução, a pesquisa comparativa ficou dividida entre vários tipos de preocupaçôes determinantes nos princípios e nas formas de intervenção e de inteligibilidade dos fenômenos educativos das abordagens que a ela se afiliavam. Como todo campo de pesquisa, ela é atravessada por tensões, rupturas e formas de exposição institucionais contrastadas. ${ }^{1}$ Cada período dessa evolução tem sua épistémè, sua grade de análise, e vê-se impor "racionalidades científicas", de forma mais ou menos consentida. Entretanto, seria um abuso considerar todas essas culturas comparatistas passadas ou contemporâneas como tradições claramente circunscritas e lineares. Elas são antes componentes sucessivos do discurso comparatista, trabalhados por modelos subjacentes, imaginários científicos (com suas retóricas próprias) e interesses de 
conhecimento específicos, discerníveis em momentos-chave do desenvolvimento histórico quer da especialidade, das ciências sociais em geral, ou dos campos culturais que constituem seu âmbito de expressão.

Embora distintas em seu projeto científico ou método, algumas abordagens compartilham, entretanto, um fundo comum e solidariedades científicas ou ideológicas. Assim, os dois primeiros componentes apontados no discurso comparatista - o determinismo e o pragmatismo - abrangem quatro tipos de abordagens: positivista e "naciocentrista", por um lado, e evolucionista e intervencionista, por outro. Todas, a títulos diversos, que vamos explorar, constituem expressões singulares e autônomas do programa - tanto científico como societal - da modernidade. $\mathrm{O}$ terceiro componente - a crítica - constitui uma denegação das perspectivas anteriores, mais particularmente do seu consensualismo e da sorte que reservam ao outro, que reificam mais do que compreendem. Quanto aos componentes mais recentes do discurso comparatista, a globalização e a hermenêutica, que só fazem sentido à luz dos que os precedem, e caracterizam o que se convém chamar, por conseguinte, e por falta de termo melhor, a pós-modernidade, eles enfrentam um certo número de reviravoltas socioculturais e políticas que trabalham o período contemporâneo. A partir dessa perspectiva histórica dos imaginários científicos e das retóricas sucessivas da educação comparada, poderemos discernir os desafios que a pesquisa comparativa enfrenta em razão do que identificaremos como uma extensão da contemporaneidade.

\section{Os componentes modernos do projeto comparatista}

\section{$\mathrm{O}$ determinismo}

Esse componente exprime duas grandes narrativas da modernidade: a fé no progresso científico e a fé no sistema político do EstadoNação. Nesses dois casos, é a idéia de um sistema acabado que prevalece, e que, de um ponto de vista científico, exprime-se com o positivismo e, de um ponto de vista político, com a edificação e o desabrochar dos Estados-Nações. Este ideal de fechamento se desenvolveu no campo nascente da educação comparada em dois planos: o da ciência (positivismo) e o da história ("naciocentrismo"). 


\section{$O$ determinismo cientifico: o positivismo}

Desde as origens deste campo de estudos, o projeto de fundação de uma ciência comparada da educação somente pode ser compreendido quando posto em perspectiva com o programa filosófico e político da modernidade, e ao mesmo tempo com o desenvolvimento e a estruturação das disciplinas científicas e sua ancoragem universitária à véspera do século XIX. Por sua ambição de transpor para as ciências humanas e sociais em plena expansão os métodos próprios das ciências da natureza, como ocorrera com a anatomia (de Cuvier, 1805), o direito (Feuerbach, 1810) e a antropologia (Humboldt, 1795), o projeto comparatista inscreve-se em cheio nessa agenda. Portanto, os fundadores do comparatismo em educação ambicionavam construir uma concepção e métodos positivos no campo da educação. Essa concepção positivista da educação comparada buscava definir leis universais a respeito das doutrinas pedagógicas e do funcionamento dos sistemas educativos nacionais, projeto científico que seria reafirmado no campo sociológico, no final do século XIX, por E. Durkheim (1895), a comparação sendo então erigida em princípio metodológico de produção de conhecimentos em ciências sociais (Schriewer, 1997a). Essa abordagem naturalista dos fatos e sistemas educativos nacionais pensava seus objetos de estudo privilegiados como unidades de análise estável, como entidades independentes.

A ancoragem filosófica e histórica da educação comparada é evidente nessa concepção cientificista que exprime um dos mitos fundadores da modernidade: a fé numa correlação entre progresso científico e progresso social (o saber científico tirando seu valor de sua utilidade social) e a idéia de que os Estados-Nações em via de edificação perseguiam ambições comuns e universais (Glenn, 1988). Essa tendência, que aliava consensualismo e cientificismo, já pode ser encontrada no texto pioneiro de M.-A. Jullien de Paris, de 1817, que evoca

o projeto de uma grande empreitada, (...) essa tendência universal rumo a uma mesma meta, a regeneração e o aperfeiçoamento da educação pública (...) Parece portanto necessário formar para essa ciência, como ocorreu com outros ramos de nossos conhecimentos, coleções de fatos e observações (...) para deles deduzir princípios certos, regras determinadas, e assim fazer da educação uma ciência aproximadamente positiva. (Jullien de Paris, 1962, p. 8 e 13) 
Inscrita na modernidade, essa tendência positivista se caracteriza por uma concepção descritiva e estática do conhecimento. Contudo, essas ambições não passariam de programa por mais de um século, em que foram desenvolvidas principalmente abordagens historicistas. Nos anos de 1960, sob a influência do estruturalismo hegemônico, assistimos a uma ressurreição desse componente positivista. Nesse período de efervescência do campo, é mais uma vez a edificação de um "método comparativo" que está no cerne do projeto comparatista, graças ao desenvolvimento e à sofisticação das ferramentas de pesquisa quantitativa, que vêm atualizar a ambição mais que centenária de constituir uma ciência comparativa que permita elaborar prediçóes e teorias gerais dos fatos educativos. A. Pzeworski observa, a este respeito, que o comparatismo da época é marcado por um paradoxo, que toma a forma de "um consenso acerca da idéia de que a educação comparada não consiste em comparar, mas em explicar"2 (Pzeworski, 1987, p. 35).

Harold Noah e Max Eckstein incluem-se entre os principais promotores dessa concepção neopositivista do comparatismo (Noah \& Eckstein, 1969). Num contexto de consolidação dos métodos objetivantes, as abordagens em vigor durante esse período, metodologicamente armadas, assumem a herança durkheimiana, e reafirmam fortemente o princípio fundador da educação comparada, a saber, seu caráter essencialmente explicativo e exógeno. Em razão do prestígio que essas abordagens legiferantes conheciam na época, W. D. Halls deduz que "a geração precedente de comparatistas apenas percebia de maneira difusa que o método comparatista, por ser analógico, era um substituto do método experimental das ciências exatas" (Halls, 1990, p. 33). Fascinado pelo ideal positivista de generalização e de fechamento, o determinismo científico acabaria logo sofrendo a concorrência de abordagens que ultrapassariam a perspectiva positivista, ao aliarem pragmatismo e evolucionismo social.

\section{O determinismo histórico: o "naciocentrismo"}

Herdeira das grandes narrativas da modernidade sobre as quais o projeto comparatista deitou suas bases, essa concepção da educação comparada toma como unidade de análise os sistemas educativos nacionais e se propõe desvendar seus grandes princípios de organização. Participando de uma concepção substancialista do "caráter nacional" (Sadler, 1979) dos diferentes sistemas de ensino, essa tendência, contudo, é menos pre- 
Do Estado-nação ao espaço-mundo...

ocupada em fornecer um método para o campo comparativo que em descrever e, sobretudo, caracterizar os sistemas educativos estrangeiros, esperando desvendar as causas históricas de seu desenvolvimento e de sua organização. Apesar do relativismo dessas abordagens, existe um fundo comum entre as correntes positivista e "naciocentrista": sua concepção fechada do conhecimento. A explicação e o enciclopedismo foram por muito tempo as formas privilegiadas do campo comparativo para tender a este ideal moderno de fechamento.

Esse segundo componente exprime fortemente um outro mito fundador da modernidade, o poder de integração e de fechamento da nação, ${ }^{3}$ forma de organização política de uma "comunidade solidária" (Renan, 1993, p. 45), a partir da qual o século XIX pariu, de forma moderna, o Estado-Nação. Essa fé se apóia num princípio forte, enunciado pelo sociólogo W. G. Sumner (1840-1910), que quer que toda comunidade humana se defina como grupo interior (in-group) que se distingue dos grupos externos (out-groups). ${ }^{4} \mathrm{O}$ "grupo-nós" define-se tanto pelo que o mantém junto como - negativamente - pelos "outros", dos quais se distingue. ${ }^{5}$ Ao colocar a identificação comunitária e o sentimento coletivo de pertencimento nacional como as bases de um espaço político que se apóia no "princípio primordial da humanidade eterna" (Schulze, 1996, p. 21), a modernidade instituiu a figura do Outro. Essa fundação moderna da alteridade vai constituir o horizonte de referência comum para gerações de comparatistas.

Esse componente "naciocentrista", recorrente no campo da educação comparada desde suas origens, esteve na base do desenvolvimento do campo de estudo no século XIX, ao longo do qual, na hora da "sistematização da educação" (Müller et al., 1987), administradores, políticos e filósofos perceberam o conhecimento de outros contextos nacionais como um meio de organizar e melhorar seu próprio sistema educativo, ele mesmo em fase de edificação. Uns pioneiros da educação moderna como Victor Cousin, na França, Horace Mann ou ainda Henry Barnard, nos Estados-Unidos, Friedrich Thiersch, na Alemanha, empreenderam longas investigações dos sistemas educativos estrangeiros, na esperança de importar inovaçôes para seus próprios países. Deste ponto de vista, o componente "naciocentrista" do comparatismo está estreitamente vinculado ao programa da modernidade, pois acompanha, no plano da educação, "a expansão sistêmica" que comandou o movimento de edificação de uma ordem societal inclusiva fundamentada no Estado-Nação (Luhman, 1995; Schriewer et al., 2000). 
Embora marcadas como tendências cientificistas pela ideologia progressista, as abordagens "naciocentristas", pela acumulação de conhecimentos a respeito dos sistemas nacionais de educação, encontram bases para garantir a prosperidade de seu próprio sistema de ensino (Arnold, 1861; Sandiford, 1918).

Contudo, desde o começo do século XX, o comparatista inglês Michael Sadler, de quem Isaak Kandel (1930), Robert Ulich (1961) e Nicholas Hans (1949) foram os herdeiros, advertia contra a tentação de importar sem precaução experiências no campo educativo observadas em outros contextos culturais: "Não se pode vaguear à vontade nos sistemas educativos do mundo inteiro [escreve Sadler], como uma criança que brinca num jardim, e colhe, aqui e acolá, uma flor de um matinho, folhas de outro, e esperar que, ao plantarmos em nosso próprio jardim o produto dessa colheita, dela brote uma planta nova" (Sadler, 1979, p. 49).

Como na perspectiva positivista, o consensualismo - isto é, a fé positivista nas virtudes pacificadoras do conhecimento - constitui o fundamento dessa concepção do comparatismo. O ideal de fechamento que o "naciocentrismo" compartilha com a abordagem cientificista faz com que privilegie, dessa forma, uma perspectiva continuista, mais "justapositiva" que propriamente comparativa, dos fenômenos educativos (Cramer \& Browne, 1956; Mallinson, 1957).

\section{$\mathrm{O}$ pragmatismo}

Se as origens da educação comparada são marcadas por preocupações progressistas e modernizadoras, é no período de reconstrução e de reforma da educação que os países ocidentais, em sua maioria, conheceram depois da guerra que o componente pragmático da educação comparada desabrochou. Marcadas pela segunda guerra mundial, as Nações que dela participaram investiram a educação comparada como um ideal de intercompreensão e de pacificação das relações internacionais, o qual favoreceu a criação dos principais organismos internacionais. Desde então, o sentimento da solidariedade das nações constituiu o princípio regulador do comparatismo (World Yearbook of Education, 1948-1951). Essas preocupações situam este componente pragmático no prolongamento do projeto moderno e da lenta empreitada de unificação nacional, empreitada marcada, nesse ínterim, por duas guerras mundiais que revelaram 
Do Estado-nação ao espaço-mundo...

os efeitos da exaltação da "mente nacional" e as falhas das instituições democráticas quando postas a serviço do retraimento identitário. ${ }^{6}$

\section{O evolucionismo social}

É tanto uma esperança de convivência pacificada quanto um desejo de ajudar as decisões políticas que atravessam o componente pragmático em sua vertente evolucionista, ambos associados às preocupaçôes científicas que surgem progressivamente das abordagens neopositivistas para inspirar, no mesmo movimento, o pragmatismo de J. Dewey e o racionalismo crítico de K. Popper.

Se o pano de fundo civilizacional das duas tendências - neopositivista e evolucionista - é o mesmo, seus postulados epistemológicos são obviamente distintos. Na perspectiva do evolucionismo social, a educação comparada é considerada uma ferramenta privilegiada de ajuda à decisão e, eventualmente, um instrumento de legitimação de ações reformadoras. Diferentemente das perspectivas precedentes, essencialistas ("naciocentrismo") ou positivistas, ela investe os problemas educativos encontrados em diferentes contextos socioculturais como tantas "teorias encarnadas" (K. Popper), sobre as quais formula hipóteses e propostas de sentido colocadas a serviço da esfera política. Deste ponto de vista, essa abordagem do comparatismo é ao mesmo tempo a realização e a superação das concepções positivistas que trabalhavam o campo desde suas origens. Deste projeto originário, ela conserva a ambição de cientificidade e o consensualismo, mas abandona as veleidades de generalizabilidade e, portanto, de fechamento do conhecimento. Não indutiva, a perspectiva do evolucionismo social afirma com força, em contrapartida, o caráter operacional dos conhecimentos produzidos e sua fé no progresso social. Neste sentido ela se reveste, no plano político-filosófico, da forma do liberalismo reformista, projeto que desabrochará durante a segunda metade do século XX.

A abordagem dita "resolução de problemas" (problem-approach), desenvolvida por Brian Holmes (Holmes, 1958), é uma etapa importante na consolidação dessa perspectiva pragmático-evolucionista. Como ela não toma mais macrocontextos educativos como âmbito de comparação, mas focaliza sua análise em fenômenos contextuais circunscritos, essa abordagem é caracterizada ao mesmo tempo por sua ambição científica e por preocupações pragmáticas e operacionais agudas. Não se trata mais 
de definir caracteres nacionais, nem mesmo princípios universais, mas de elaborar hipóteses a partir do exame de contextos e, com isso, de fornecer ideais-tipos suscetíveis de ajudarem a esfera política na implementação de soluções políticas num contexto preciso (Holmes, 1965; King, 1968).

\section{$O$ intervencionismo}

Do mesmo modo que o período imediato do pós-guerra havia sido marcado por preocupações de pacificação das relações internacionais em democracias ocidentais traumatizadas e atentas em neutralizar os riscos dos nacionalismos, o fim dos anos de 1950 é marcado pelo crescimento de um interesse na assistência tecnológica e no investimento econômico em educação nos países em desenvolvimento, principalmente sob a impulsão dos economistas (World Yearbook of Education, 1954-1956). ${ }^{7}$

Essas perspectivas se beneficiaram do apoio aos países em vias de desenvolvimento por infra-estruturas internacionais, como o Banco Mundial ou a UNESCO, e mais tarde a OCDE, para os países europeus, que têm usado, desde os anos de 1960, pesquisas de campo quantitativas sistemáticas como instrumentos de pilotagem das políticas e das reformas educativas. Se, com o desenvolvimento dos organismos internacionais e das ferramentas de planejamento da educação, o comparatismo ampliou progressivamente seu campo de estudos e de intervenção, mais particularmente em direção aos países menos adiantados, às vezes isso se deu ao preço de conflitos a respeito do alcance ideológico dessas abordagens. Os defensores dessa concepção da educação comparada consideram que a comparação tem por principal missão acompanhar os processos de modernização social e guiar as reformas educativas necessárias no campo da educação (Psacharopoulos \& Woodhall, 1985; Psacharopoulos, 1990).

Menos escorada metodologicamente que a perspectiva do evolucionismo social, essa tendência é de certa forma menos pragmática, pois mais descritiva. Entretanto, ela evoluiu desde os anos de 1970, e não se ateve mais à única edificação de tabelas estatísticas e a simples avaliaçóes exógenas e padronizadas dos sistemas educativos, mas, desde então, preocupou-se em avaliar a adaptabilidade dos sistemas, em proceder a um acompanhamento dos programas de reformas e em melhorar os sistemas de informação. 
Do Estado-nação ao espaço-mundo...

Nessa perspectiva de "pesquisa aplicada" (Debeauvais, 1997, p. 99), a perícia do comparatista consiste em avaliar a eficiência dos investimentos em educação, seus rendimentos e suas implicações sociais, econômicas e políticas. Por favorecer, pela difusão de modelos culturais, educacionais e sociais, uma interação forte entre os países industrializados e os países menos adiantados colocados em situação de dependência, essa tendência intervencionista do comparatismo em educação prepara a imposição progressiva de um espaço ampliado - global ou mundial - de inteligibilidade dos fenômenos educativos (Meyer et al., 1977). A simplificação e a negligência das especificidades nacionais - apesar de uma evolução rumo a indicadores de desenvolvimento mais qualitativos e a espaços de estudo mais limitados -, e uma forma de paternalismo econômico e político, estão entre as principais queixas dirigidas a essa concepção do comparatismo em educação (Carnoy, 1974), que abrirão o caminho para uma concepção crítica do comparatismo (infra).

A essas tensões ideológicas acrescenta-se uma discordância epistemológica nas abordagens que se inscrevem numa concepção pragmática do comparatismo em educação: o registro e o tempo de ação do político e do científico são por natureza discordantes. A avaliação dos sistemas de educação ou de formação não significa necessariamente um entendimento dos fenômenos culturais que abrigam. ${ }^{8} \mathrm{O}$ discurso da pesquisa e o discurso da perícia, que $\mathrm{H}$. Zander identifica como um "discurso com estatuto administrador" (1996, p. 284), inscrevem-se em registros discursivos e de interesses de conhecimento diferentes, o primeiro sendo trabalhado por uma preocupação epistemológica de questionamento e de problematização dos fenômenos educativos, e o segundo, por preocupaçóes pragmáticas de avaliação e de pilotagem dos sistemas educativos. ${ }^{9}$

Dificilmente conciliáveis, essas práticas discursivas divididas constituiriam um fator de fragilização para o campo, apesar de sua aparente vitalidade. Quase 20 anos atrás, J. J. Noah já admitia que "a educação comparada constitu[ia] um campo de estudo aplicado que encontr[ava] primeiro sua justificativa na sua contribuição para a avaliação, a gestão educativa, a administração e na ajuda à decisão política. Entretanto, [acrescentava], como todo campo, seus resultados são potencialmente submetidos a um uso abusivo para legitimar tal ou tal ação reformadora" (Noah, 1984, p. 161). Num campo confrontado com a multiplicação de "novos consumidores de educação comparada, (...) planejadores, peritos, agências de financiamento, organizações não-governamentais (...)” 
(Nóvoa, 2000, p. 203), tantos atores que gozam de uma grande influência no espaço internacional da educação, prevenir-se contra o crescimento de uma deriva utilitarista é uma das preocupações contemporâneas para os comparatistas que querem construir e preservar a legitimidade científica do campo de estudos, que a heterogeneidade das instâncias do discurso comparatista tende a ameaçar.

Como hesitam entre hermetismo e externalismo, os comparatistas em educação estão sujeitos a incertezas identitárias recorrentes. E, no melhor dos casos, difícil encontrar um equilíbrio entre, por um lado, um isolacionismo científico preocupado em preservar o campo da impureza acadêmica do discurso perito, que é então comodamente incluído na categoria "educação internacional", oposta à "educação comparada" (assim como ocorre no mundo anglo-saxão), e, por outro lado, uma abertura e uma confrontação saudáveis, ${ }^{10}$ mas suscetíveis de colocar em perigo os alicerces teóricos e a legitimidade acadêmica da especialidade. Em razão da multiplicidade de suas ancoragens institucionais, de seus objetos e de seus usos, o campo da educação comparada torna ainda mais sensível essa tensão entre internalismo e externalismo científicos, a qual trabalha de modo recorrente a pesquisa educacional. ${ }^{11}$

\section{O comparatismo crítico: uma ruptura ideológica}

O componente crítico do discurso comparatista desenvolveu-se no campo da pesquisa comparativa em educação como uma reação contra:

a) as concepções objetivistas e fechadas dos fenômenos educativos e culturais que o funcionalismo tende a promover;

b) as perspectivas do evolucionismo social que, cegadas por uma concepção continuísta da história e uma abordagem pragmática dos fatos educativos, tende a descuidar dos processos de mudança social;

c) o consensualismo, que impede a empreitada científica de questionar seus fins, o que constitui o melhor meio de eludi-los, sobretudo quando os espaços de intervenção ultrapassam as fronteiras nacionais.

Examinemos esses diferentes pontos de ruptura das abordagens críticas com uma "tradição" comparatista em educação que, no plano político, toma a forma do liberalismo reformista. 
Do Estado-nação ao espaço-mundo...

Portanto, essa perspectiva se erige contra formas de comparação consensualistas que encarnam, por seu etnocentrismo, uma forma moderna de colonialismo - os países desenvolvidos (geralmente as antigas potências coloniais) exercem, ou perenizam por sua perícia, um poder de controle sobre o desenvolvimento de países menos adiantados (Carnoy, 1974; Noah, 1984). A educação comparada, em seu programa pragmático, desabrochou dentro de um período pós-colonial, durante o qual a educação e a ajuda ao desenvolvimento representaram, para o Ocidente, os instrumentos de seu expansionismo cultural e ideológico, e com isso, um meio de assentar para si mesmo sua própria identidade, erigida sobre esses fundamentos universalistas (Horowitz, 1972; Spivak, 1999).

Ao passo que as perspectivas "clássicas" - tanto deterministas como pragmáticas - eram marcadas ao mesmo tempo pelo consensualismo e pelo universalismo, a perspectiva crítica, em conformidade com o que, para boa parte de seus representantes, constitui sua teoria de referência o marxismo -, desenvolve uma leitura descontinuísta da História. Abalando a vontade hegemônica ideológica que vigorava, encoberta de cientificidade (Welch, 1985), nas correntes tradicionais da educação comparada esse componente crítico, movido pelas teorias do conflito, concebe a sociedade como um espaço de contestação social e, por conseguinte, faz dos processos de mudança social os "objetos" privilegiados da educação comparada (Altbach \& Kelly, 1978, 1992; Bowers, 1993; Carnoy \& Samoff, 1990; Welch, 1993).

Essa abordagem se inscreve numa guinada crítica que excede o campo da educação comparada e também afetou a antropologia e a sociologia. No cerne dessas abordagens críticas e para além da estigmatização ideológica, encontramos a questão do tratamento do Outro e da cultura pelos comparatistas, desde as origens do campo. Portanto, são preocupações tão científicas quanto éticas que trabalham o conjunto dessa corrente. D. H. Hoffman enfatiza o que constitui, segundo ela, o paradoxo recorrente da educação comparada: "Colocar o observador externo (outsider) numa posição curiosa, a de avaliar o que nem sequer se dá os meios de compreender" (1999, p. 471).

As preocupaçôes ideológicas desse componente crítico do comparatismo foram progressivamente deslocadas para um plano metodológico. Essas abordagens substituem a concepção exógena da comparação, que caracterizava as tradiçóes "naturalistas" dominantes desde as origens da educação comparada, por uma perspectiva emancipadora que a tradição 
anglo-saxã designa com o nome de empowerment, e que se distingue das abordagens tradicionais pelo fato de, em vez de implementar uma perícia externa encarregada de tratar dos problemas educativos, desenvolver metodologias preocupadas, mais localmente, em esclarecer processos de apropriação dos fenômenos educativos pelos próprios atores, por meio da conscientização (Altbach \& Kelly, 1986). O desenvolvimento de métodos de inspiração fenomenológica (Hunter, 1994) manifesta o deslocamento progressivo do interesse de conhecimento do comparatismo dos fatos para os processos educativos, e uma atenção mais forte para o sentido dos fenômenos educativos (Crossley \& Vulyami, 1984; Heyman, 1979; Masemann, 1982).

\section{As conseqüências da modernidade: uma ruptura epistêmica ${ }^{12}$}

Os desafios da globalização - e de sua contraparte intranacional, a fragmentação - parecem se impor, hoje em dia, em todas as mentes. Que realidades culturais, políticas, civilizacionais essa retórica do consenso que vem substituir outra - recobre, e que desafios essas tendências auguram para o campo da educação comparada? Examinaremos como a pesquisa comparativa dá conta dessas evoluções civilizacionais.

\section{A globalização}

Se o Estado-Nação tradicionalmente constituiu - e continua constituindo - a unidade mais comum de análise, o padrão do comparatista, as áreas de influência ideológica compuseram, por muito tempo, uma outra forma, menos visível, mas tão pregnante quanto, de organização espacial desse campo de estudos. ${ }^{13}$ De uma maneira que, provavelmente, não é alheia ao enfraquecimento das ideologias, outros espaços de comparação emergem, divididos entre o nível global e o nível local, entre, por um lado, a exigência de levar em conta a intensificação da circulação da cultura e das pessoas e, por outro, a influência recíproca entre contextos socioculturais afastados, o que leva menos a uma uniformização transnacional dos modelos sociais do que a formas singulares de apropriação, por "comunidades interpretativas", de fenômenos convergentes (Featherstone, 1990; Nóvoa, 2000) e, além disso, à necessidade correlata de ver reconhecidos e tomados em consideração espaços identitários mais restritos que o espaço nacional (Arnove \& Torres, 1999; Smith, 1992). 
"Se os outros são menos outros, o mesmo não é mais o mesmo, ele se torna mais complexo, divide-se, diferencia-se” (Augé, 1994, p. 83). A globalização e a fragmentação, isto é, o crescimento de reivindicações particularistas de reconhecimento e de identidade de "comunidades imaginárias" (Anderson, 1991), participam na verdade de um mesmo processo de ampliação dos quadros espaciotemporais construídos pela modernidade, que se tornaram "pequenos demais para os grandes problemas da vida, e grandes demais para os pequenos problemas da vida” (Bell, 1987, citado por Giddens, 1994), e dos quais o Estado-Nação, única organização política que a modernidade tenha produzido, segundo Max Weber, constitui um dos pilares (Kastoryano, 1998). ${ }^{14}$

Essa tensão entre o global e o local, que alguns designam pelo conceito de glocalisation (Robertson, 1995), mostra, mais particularmente no contexto europeu, o quanto a integração supranacional participa ao mesmo tempo de uma fragmentação intranacional, pela dinamização das regiōes (Scardili, 1993). Essas evoluçôes geram tensões internas entre os comparatistas, entre os defensores de um comparatismo que se desenvolve além mesmo dos quadros nacionais e os que desejam que a comparação se arraigue nas realidades culturais e econômicas regionais. Não há contradição, na realidade, pois "a transformação local faz parte da globalização tanto quanto a ampliação lateral das relações sociais por meio do tempo e do espaço" (Giddens, 1994, p. 70).

Apoiados, em particular, sobre a teoria dos sistemas desenvolvida por Niklas Luhman (1984), os promotores da perspectiva globalizante em educação comparada estimam que as mudanças civilizacionais que vêm afetando nossas sociedades desde os últimos 25 anos do século XX equivalem às que conheceram durante todo o século XIX (Schriewer, 1997b). Portanto, o Estado-Nação constituiu o princípio organizador dos sistemas nacionais de educação (Wallerstein, 1974, 1991). Marcado pelo expansionismo cultural do pós-guerra, o período contemporâneo seria caracterizado pelo enfraquecimento da vocação inclusive do Estado-Nação. Essa intensificação da difusão cultural e do desenvolvimento de redes de interdependência transnacionais tornaria caduca a compreensão dos fenômenos educativos na única luz das formas societais e políticas construídas pela modernidade (Schriewer, 1997a, 2000). Caberia então, para o comparatista, repensar os quadros espaciais da educação comparada em função das novas formas de regulação política e de difusão cultural e educacional (Rose, 1999). 
É o que estão tentado fazer as pesquisas que registram uma expansão mundial dos modelos educativos herdados dos sistemas modernos de educação tais como foram edificados na Europa (Ramirez \& Boli, 1987). Apoiado em infra-estruturas de difusão e de informação de peso (UNESCO, Banco Mundial, IIPE), o expansionismo cultural do período pós-guerra favoreceu uma interdependência crescente dos sistemas educativos nacionais que obriga a não pensar mais sua evolução em referência apenas a processos intranacionais.

Contudo, não é a inércia dos sistemas educativos nacionais que as abordagens da globalização registram, mas, pelo contrário, as transformações que a transposição de modelos educativos, elaborados dentro de e para outros espaços culturais, para contextos sociais ricos de uma cultura e de tradiçôes próprias não deixa de gerar localmente (Badie, 1992; McGrew, 1992). Nessa perspectiva sistêmica, o projeto dessas abordagens, em suma, é o de propor uma análise sistemática das condiçōes de homeóstase de sistemas educativos submetidos a uma intensificação das relações de interdependência.

\section{A hermenêutica}

"É difícil identificar um tempo mais quente para a educação comparada”, declarava, recentemente, A. Nóvoa (2000). De fato, a emergência de novos espaços identitários, como a Europa, e de problemáticas educativas transnacionais obriga o comparatista a um reenquadramento de suas unidades de análise tradicional. A abordagem da globalização é uma das conseqüências dessas evoluçôes no campo comparativo. Para certos comparatistas, essa necessidade de repensar os quadros espaciais da pesquisa comparativa acompanha a preocupação de integrar o sócio-histórico na inteligibilidade dos processos educativos. A tendência hermenêutica mais recente está atenta à racionalidade dos atores educativos e às modalidades de construção dos imaginários sociais (Nóvoa, 1995, 1998). A partir dessa concepção construtivista da comparação em educação, o desafio é menos dar conta de fatos educativos do que tornar historicamente inteligíveis processos que se desenvolvem em comunidades humanas que constroem, discursivamente, sentido e identidades (Schriewer, 1998). Essa tendência histórico-hermenêutica promove uma concepção da cultura como texto, uma cultura "fabricada como uma ficção" (Popkewitz et al., 2001, p. IX). 
Do Estado-nação ao espaço-mundo...

Nessa perspectiva que rompe com a "narração evolucionista" (Giddens, 1994) da modernidade, "a análise não toma mais como referência contextos definidos segundo a visibilidade de seus contornos geográficos, políticos ou sociais, mas contextos definidos segundo a invisibilidade das práticas discursivas que lhes dão sentido" (Nóvoa, 1995, p. 40). Desconfiando das ideologias progressistas e exógenas que, por muito tempo, trabalharam o campo, essa tendência contemporânea substitui progressivamente um modelo contextual e pragmático por um modelo textual que traduz a centralidade do discurso na construção dos fenômenos educativos. Apoiados nos avanços da filosofia continental, mais especificamente a fenomenologia hermenêutica de P. Ricoeur, a epistemologia histórica de M. Foucault e a ética argumentativa de J. Habermas, ${ }^{15}$ os defensores dessa abordagem histórico-hermenêutica dos fenômenos educativos e culturais postulam que a tarefa do historiador passa por uma reconstrução narrativa do passado, "uma dimensão construtiva que ligue a história à tradição literária mais do que ao relato da ciência” (Nóvoa, 2001, p. 46, na esteira de Ricœur, 1994).

A esse título, a perspectiva hermenêutica é, provavelmente, a que rompe mais radicalmente com as origens do campo comparativo, ao mesmo tempo no seu desígnio científico e societal (o comparatista livra-se das preocupações cientificistas, pragmáticas ou reformadoras), nas suas unidades de análise (que não se impõem mais a priori segundo fronteiras políticas, mas segundo formas de composição de comunidades imaginárias - Anderson, 1991) e nos seus postulados epistemológicos (a arqueologia histórica deixa de ser a narrativa do progresso, da História com " $\mathrm{H}$ " maiúsculo, para se tornar o desvendamento da diversidade histórica e cultural da humanidade, a valorização das colocações em intriga sucessivas e ancoradas no presente de uma cultura e dos discursos que esta sustenta sobre si mesma). Os trabalhos de T. S. Popkewitz sobre os currículos escolares, nos quais o autor se esforça por instruir uma "epistemologia social da escola", por exemplo, participam de uma abordagem hermenêutica das metanarrativas das culturas educativas (Popkewitz, 1987, 2001).

A este respeito, esse projeto hermenêutico e historiográfico apresenta um traço comum com o componente crítico evocado acima, mesmo se seus quadros de referências teóricas e postulados epistemológicos são completamente distintos. Ao se confrontar tanto com os metatextos da cultura como com a ação e com as práticas "autóctones", essa tendên- 
cia também adota uma postura crítica e evidencia preocupações emancipadoras (Grosvenor et al., 1999; Hunter, 1994; Rose, 1999). Nesse projeto de uma hermenêutica generalizada dos fenômenos educativos e culturais existe a mesma preocupação de reabilitação da palavra encarnada, ou seja, do sujeito.

\section{A ampliação da contemporaneidade: novo desafio de conhecimento para a educação comparada}

O fim das ideologias e das "grandes narrativas" da modernidade o positivismo, o progressismo, o evolucionismo, o marxismo - inaugurou, segundo Lyotard (1979), uma era de incerteza que deixa o mundo com falta de pontos de referência e de crenças. Essa constatação, muito conhecida e discutida (Giddens, 1994), alimenta o sincretismo e um relativismo generalizado. Não nos cabe, aqui, discutir sua pertinência. Entretanto, nesse período de indecisão, em que as noções de globalização e de mundialização ressoam às vezes como invocações - com o risco de irritar (Slama, 1993) - e, eventualmente, alimentam concepções fatalistas do desenvolvimento cultural de nossas sociedades (Bennett, 2001), sujeitadas a fenômenos que as ultrapassam e as submetem à sua lógica implacável, e até mesmo ameaçam sufocar as diferenças - e nisto a figura do Outro, que dá seu sentido ao comparatismo -, o desafio é enorme para a educação comparada. A falta de poder mobilizador da retórica da globalização, ou mais localmente da "europeização", pode, de fato, gerar fenômenos regressivos, de retraimento identitário, o que, por sinal, ocorre de vez em quando.

As ideologias têm isso de particular que, por serem crenças que pretendem à verdade e, portanto, à exclusão de todas as outras, por muito tempo, desempenharam, em nossas sociedades modernas, o papel antigamente reservado às religiōes e aos mitos, pois, como estes, fornecem uma leitura da sociedade e de suas finalidades próprias: "A narração mítica traz a rede de significados pela qual se exprime e se pensa a ordem do mundo na sua totalidade" (Ansart, 1977, p. 23). Ora, se a sociedade constituía o espaço de referência no modelo marxista, não é mais o caso no modelo liberal, no qual ela se torna um componente entre outros de um sistema global de regulação do capital financeiro, intelectual, cultural, educacional (Castells, 1996). Nesse vão deixado pela derrota das ideologias e pelo crescimento de uma retórica mais "realista", há, prova- 
Do Estado-nação ao espaço-mundo...

velmente, a marca daquele desencanto do mundo anunciado por Max Weber, isto é, o triunfo de uma racionalidade instrumental única, ao preço de uma forma de irracionalismo axiológico.

Entretanto, as ideologias não arrastaram os imaginários sociais, substratos de toda comunidade cultural, na sua queda. $\mathrm{O}$ componente hermenêutico do discurso comparatista, que pensa a cultura como texto, promove uma perspectiva antropológica e sócio-histórica da educação, que permite reintroduzir sentido, vínculo, o das solidariedades simbólicas que reúnem comunidades culturais. Portanto, as "conseqüências da modernidade", para a educação comparada, são abordagens que são, singular e simultaneamente, globalizantes e subjetivantes.

Embora se distingam das concepções exógenas que marcaram o campo da educação comparada e trabalhem para uma refundição epistemológica do campo que passa por um necessário reexame de seus objetos epistêmicos tradicionais, esses componentes contemporâneos do comparatismo mantêm uma solidariedade científica que encontra seus limites nas ferramentas que privilegiam para analisar os objetos que se dão. A abordagem sistêmica de Luhman, que inspira as abordagens da globalização em educação, é pouco compatível com a perspectiva hermenêutica de um Ricœur ou a ética reconstrutiva de um Habermas, nas quais se inspiram comparatistas como Nóvoa. Em todos os casos, mesmo se ambas são esse "permanecer junto" de comunidades humanas engajadas em espaços sociais com contornos espaciotemporais menos determinados, as solidariedades simbólicas, propriamente humanas, que a abordagem histórico-hermenêutica toma como objeto não podem se confundir com as coesões sistêmicas que as abordagens da globalização analisam.

Ao fim deste sobrevôo do campo comparativo em educação, está claro que um componente fundador do projeto e do discurso comparatistas está em vias de ser (re)pensado de acordo com as mudanças civilizacionais contemporâneas, o que justifica que a tarefa da educação comparada não se limite mais, agora, à simples constatação de semelhanças ou dessemelhanças observáveis em diferentes contextos educativos nacionais que se tornaram estreitos: esse componente, do qual a educação comparada não pode abrir mão, é a figura do Outro. Por conseguinte, as correntes comparatistas que registram essas transformações, independentemente de seu modo, convergem para a necessária tomada em conta da ampliação da contemporaneidade. ${ }^{16}$ 
Por um lado, essa espécie de sincronização a distância entre sujeitos que, embora não compartilhem fisicamente um espaço de convivência, são, entretanto, engajados nas e aproximam-se das mesmas configuraçóes culturais e societais ${ }^{17}$ e, por outro lado, o enfraquecimento do Estado-Nação na sua vocação moderna de inclusão, que favorece o desenvolvimento de espaços de reconhecimento identitários infra ou transnacionais, constituem dois desafios de conhecimento maiores para o futuro da educação comparada, uma vez que tendem a renovar a figura do estrangeiro, construído pela idéia de Nação e, com isso, a do Outro. Disso decorre que, de fato, nesta perspectiva, haja uma falta de exotismo, mas também uma persistência da alteridade. A relação ao Outro continua sendo o ponto nodal, a referência da qual o comparatismo não pode abrir mão, mesmo deslocado nesses espaços ampliados, estirados, da contemporaneidade.

Por sinal, essa contemporaneidade ampliada altera provavelmente menos a alteridade do que a restaura. "A ausência do Outro de nosso Tempo foi seu modo de presença em nosso discurso - como objeto e como vítima." Será que o que Johannes Fabian (1983, p. 154) deplora aqui para o campo antropológico não vale para a educação comparada se considerarmos os projetos e interesses de conhecimento que por muito tempo esta se deu? De fato, o discurso comparatista, ao mesmo título que o discurso antropológico, tem ignorado o Outro, fazendo dele um objeto, muito mais freqüentemente do que tentou compreendê-lo. $\mathrm{O}$ conhecimento não pode mais ser, no presente, uma simples acumulação de informações sobre um "estrangeiro esquisito" (Valadier, 1997, p. 177), mas deve participar da "elaboração do conhecimento comum" (Augé, 1994, p. 78), comandada por essa contemporaneidade do observador e do observado.

Libertada pelas transições civilizacionais contemporâneas de suas tentações de "naturalização" do Outro, a educação comparada está hoje em dia engajada numa empreitada salutar de reavaliação de seu projeto científico, de redefinição de suas unidades e de suas ferramentas de análise. Essa tarefa de refundição conceitual, epistemológica e metodológica é muito estimulante para quem se interessa por um campo de pesquisa que, além de permitir que o descubramos, dá a pensar o Outro e, com isso, a si mesmo.

Recebido em junho de 2004 e aprovado em agosto de 2004 
Do Estado-nação ao espaço-mundo...

\section{Notas}

1. O exame das modalidades de exposição institucional de um campo científico é extremamente precioso para esclarecer seu desenvolvimento histórico e suas tensōes, mesmo se, em si, exigisse um outro estudo. É interessante, por exemplo, conhecer o tipo de contribuições que as revistas dedicadas à educação comparada publicam, pois isso permite delinear mais precisamente seus contornos. P. Broadfoot propôs um inventário desses na sua obra recente, Learning from Comparing (Alexander et al., 1999), em que fornece uma tipologia dos "estudos comparativos" publicados desde 1993 na revista comparativa britânica Education. Esse levantamento mostra que a maioria dos artigos publicados é de estudos conduzidos num único país (one country studies) (Broadfoot, 1999, p. 23-24). Em 1999, a partir de uma consulta extensiva dos artigos publicados desde 1975 em três importantes revistas anglo-americanas do gênero (Comparative Education Review, Comparative Education, International Journal of Education Development), V. Rust et al. observavam, por sua parte, a escassez de pesquisa genuinamente comparativa: menos de um terço dos estudos consultados desenvolve de fato um procedimento comparativo (Rust et al., 1999). Portanto, costumamos lidar com estudos intranacionais. Encontramos essas mesmas modalidades de exposição na maioria das obras coletivas de educação comparada, configuração que, paradoxalmente, deixa ao leitor o cuidado de comparar. Deste ponto de vista, uma parte importante desses trabalhos e revistas diz mais respeito à confrontação internacional que à comparação stricto sensu. De modo que o termo que G. Bereday (1964) propunha para designar esse tipo de trabalhos - foreign education - conviria facilmente ao conjunto do campo, se a maioria prevalecesse. Na mesma perspectiva de esclarecimento da exposição institucional da pesquisa comparativa, um exame do modo como se organizam coletivamente aqueles que fazem dela sua profissão - reunidos em associações nacionais ou internacionais - é extremamente útil, assim como a influência das editoras na difusão da educação comparada (Altbach, 1987; Sutherland, 1985). O peso das tradições acadêmicas e das ancoragens disciplinares, que os contextos institucional, social e político não podem apagar em razão do caráter internacional do campo, e o peso dos organismos nacionais no estatuto concedido à educação comparada, o lugar do campo de estudo na universidade (Groux \& Paul, 1999; Groux \& Tutiaux-Guillon, 2000; Leclercq, 1999), a existência de institutos de pesquisa especializados, a legitimidade do campo na comunidade científica, são tantos fatores ambientais que pesam sobre o desenvolvimento quantitativo e qualitativo da pesquisa comparativa em cada contexto nacional e, por conseguinte, sobre a coerência internacional do campo. A hegemonia do mundo anglo-saxão no campo da educação comparada, por exemplo - que conduz alguns a falar em seu "anglocentrismo" (Grüber, 2001) -, mereceria um exame mais aprofundado de sua realidade institucional tanto quanto de suas conseqüências científicas. Uma análise histórico-hermenêutica dos imaginários científicos e das tradiçôes intelectuais anglo-americanos, como no trabalho realizado por J. Schriewer e E. Keiner para a Alemanha e a França (Schriewer \& Keiner, 1992), por exemplo, seria extremamente útil. Embora não exista, pode-se, sem muita dificuldade, ao ler esta nota, intuir essa hegemonia vendo os interesses de conhecimento que guiaram o campo comparativo ao longo de seu desenvolvimento; o índice dessa hegemonia mais acessível ao leitor talvez seja a bibliografia do presente estudo.

2. As citaçôes provenientes de documentos em língua inglesa foram traduzidas para o francês pelo autor.

3. Como lembra H. Schulze (1996), a idéia de "nação" é muito mais antiga que a de "Estado". Herdada da Antiguidade romana, a natio, como sua etimologia sugere, designava uma comunidade humana construída sobre critérios comuns de origem, nascimento ou raça, 
sem por isso designar um espaço político. A natio opunha-se à civitas, que designava as populações e hordas que não conheciam instituições comunitárias estáveis. Na época medieval, passou a designar os grandes povos da Europa, evolução que denota a origem européia do uso moderno de Nação como Estado, que apenas toma forma na virada do século XIX, depois da Revolução Francesa, quando o Terceiro Estado (o povo) se torna o "todo": o Estado-Nação. Sobre essa questão, ver também D. Schnapper, 1994.

4. Sobre essa questão, ver Schulze, 1996, p. 115-134.

5. "Desde o começo, a desconfiança para com os vizinhos, a hostilidade e o combate foram, para as nações européias, um meio de se encontrarem” (Schulze, 1996, p. 133).

6. Por sinal, é nesse espírito que foi criado, depois da Segunda Guerra Mundial (1948), o World Yearbook of Education. Sobre essa questão, ver Holmes, 1990, p. 104.

7. Sobre essa questão, ver Kallen, 1996, e Weiler, 1982.

8. J. Schriewer considera, por exemplo, que as controvérsias que balizam a história da educação comparada "resultam de visões fundamentalmente diferentes do Outro, e que constituem o objeto do conhecimento, isto é, da oposição entre a minimização das diferenças socioculturais, para facilitar sua compreensão prática, e seu uso para a análise científica" (Schriewer, 1997, p. 113).

9. Para uma crítica dessa corrente, ver, entre outros, Nóvoa, 2001, e Schriewer, 1999.

10. Na França, por exemplo, a Association Francophone d'Éducation Comparée (Associação Francófona de Educação Comparada - AFEC), fundada em 1973 por M. Debeauvais, apresenta a especificidade, relativamente às associações anglo-saxãs, de reunir tanto universitários e pesquisadores como peritos oriundos das administrações e de organismos nacionais e internacionais.

11. Sobre essa questão, ver Bedin, 1994.

12. Seguimos aqui A. Giddens de modo deliberadamente explícito, pois esse autor estima que o que se convém chamar de "pós-modernidade" é mais a conseqüência do que a expressão de uma ruptura com o programa da modernidade, e que as configuraçôes culturais contemporâneas podem apenas ser esclarecidas por meio de um exame das formas de organização societal promovida pela modernidade. Se houve ruptura, foi no deslocamento das unidades tradicionais de inteligibilidade da atividade social, conseqüência da intensificação da difusão cultural e da interdependência crescente dos "teatros sociais" (Giddens, 1994). Em conseqüêencia, o campo da educaçáo comparada encontra-se desde então confrontado com o que reconhecemos como uma ruptura epistêmica, à qual responde com uma refundição epistemológica e um afastamento progressivo de seus postulados e quadros de análise tradicionais.

13. No passado, a definição de princípios que fundamentavam a educação comparada foi freqüentemente um argumento de legitimação ideológica, como pode atestar a maneira como os países comunistas - no caso a República Democrática Alemã - definiam seu campo de estudo em referência direta ao materialismo histórico e dialético: "A abordagem dos problemas da educação comparada como ciência é certamente diferente, sob certos aspectos importantes, das diversas concepçôes que vigem, entre os comparatistas, nos países capitalistas (...) As diferenças entre os comparatistas marxistas e os comparatistas burgueses são mais marcadas ainda quando se trata de suas visōes sobre a natureza da sociedade (...)" W. Kienitz, 1971, apud Cowen, 1990, p. 337.

14. A desvalorização das fronteiras dos Estados, oriunda da consolidação de outros espaços identitários supra ou infranacionais, é uma evolução que tem sua origem no programa da modernidade, e no triunfo da ideologia liberal. De modo que o que caracteriza nossa épo-

Educ. Soc., Campinas, vol. 25, n. 89, p. 1301-1332, Set./Dez. 2004

Disponível em <http://www.cedes.unicamp.br> 
Do Estado-nação ao espaço-mundo...

ca é menos o enfraquecimento do Estado-Nação do que o triunfo do Estado de tipo liberal. Se o Estado-Nação não parece mais servir para os fenômenos sociais, culturais e econômicos convergentes que afetam nossas sociedades, ele continua sendo, entretanto, o último baluarte para instituições livres e democráticas, e não encontrou substituto neste ponto.

15. Um aprofundamento das implicaçôes dessas referências recorrentes sobre a história cultural contemporânea é proposto por A. Nóvoa, 2001. O conjunto das contribuições reunidas na obra em que este artigo foi publicado merece atenção (Popkewitz et al., 2001).

16. O conceito de "contemporaneidade" foi teorizado, entre outros, por J. Fabian (1983) e reinvestido por M. Augé (1994) em sua crítica do discurso antropológico.

17. Essa recomposição das relações espaciotemporais é antes a obra da modernidade: A. Giddens lembra que "no contexto moderno, o lugar é cada vez mais fantasmagórico: os diferentes 'teatros' sociais são completamente penetrados e moldados por influências sociais muito remotas" (Giddens, 1994, p. 27). Entretanto, essa dissociação do tempo e do espaço que visava à sincronização da atividade social dentro de uma organização societal bem delimitada se estendeu, progressivamente, em razão da intensificação da difusão da cultura e da circulação das pessoas, o que levou a uma contemporaneidade ampliada, a qual torna mais densas as redes de interdependência e de influência recíprocas entre contextos socioculturais afastados. Portanto, esse processo dialético intensivo-extensivo tem suas origens no projeto moderno de domesticação do espaço e do tempo, de subordinação de espaços sociais afastados a um tempo unitário, padronizado, o que Giddens identifica como "a de-localização inerente ao desenvolvimento das instituições sociais modernas" (Giddens, 1994, p. 30).

\section{Referências bibliográficas}

ALEXANDER, R. Other primary schools and ours. Warwick: Centre for Research and Evaluation in Primary Education, 1996.

ALEXANDER, R.; BROADFOOT, P.; PHILIPS, D. (Ed.). Learning from comparing. New directions in comparative educational research. 2 vols. Wallingford: Symposium Books, 1999-2000.

ALTBACH, P.G.; KELLY, G.P. Education and colonialism. New York: Longman, 1978.

AlTBACH, P.G.; ARNOVE, R.; KELlY, G. (Ed.). Comparative education. New York: McMillan Publishing Company, 1982.

ALTBACH, P.G.; KELLY, G.P. New approaches to comparative education. Chicago and London: The University of Chicago Press, 1986.

ALTBACH, P.G. The knowledge context: comparative perspectives on the distribution of knowledge. Albany: State University of New York Press, 1987. 
ANDERSON, B. Imagined communities. London: Verso, 1991.

ANSART, P. Idéologies, conflits, pouvoirs. Paris: PUF, 1977.

ARNOLD, M. The popular education in France with notices of that of Holland and Switzerland. London: Longman, 1861.

ARNOVE, R.; TORRES, C.A. (Ed.). Comparative education. The dialectic of the global and the local. London: Rowman \& Littlefield Publishers, 1999.

AUGÉ, M. Pour une anthropologie des mondes contemporains. Paris: Champs Flammarion, 1994a.

AUGÉ, M. Le sens des autres. Paris: Fayard, 1994b.

BADIE, B. L'Etat importé. Essai sur l'occidentalisation de l'ordre politique. Paris: Fayard, 1992.

BECK, U. What is globalisation? Cambridge: Polity, 2000.

BEDIN, V. De l'internalisme à l'externalisme scientifique, vers la recherche praxéologique. L'année de la recherche en sciences de l'éducation. Paris: PUF, 1994.

BELL, D. The world and the United States in 2003. Daedalus, 116, 1987.

BENNETT, O. Cultural pessimism. Narratives of decline in the postmodern world. Edinburgh: Edinburgh University Press, 2001.

BEREDAY, G.Z.F. Comparative method in education. New York: Holt, Rinehart and Winston, 1964.

BOWERS, C. Critical essays on education, modernity, and the recovery of ecological imperative. New York: Teachers College Press, 1993.

BROADFOOT, P.; OSBORN, M.; GILLY, M.; BUCHER, A. Perceptions of teaching. Primary school teachers in England and France. London: Cassell, 1993.

BROADFOOT, P. Not so much a context, more a way of life? Comparative education in the 1990's. In: Alexander, R.; Broadfoot, P.; Philips, D. (Ed.). Learning from comparing. New directions in 
Do Estado-nação ao espaço-mundo...

comparative educational research. V. 1. Wallingford: Symposium Books, 1999. p. 21-32.

BURNS, R.J.; WELCH, A.R. Contemporary perspectives in comparative education. New York: Garland, 1992.

CARNOY, M. Education as cultural imperialism. New York: McKay, 1974.

CARNOY, M.; SAMOFF, J. Education and social transition in the Thirld World. Princeton, N.J.: Princeton University Press, 1990.

CASTELLS, M. La société en réseaux. V. 1: L'ére de l'information. Paris: Fayard, 1996.

COWEN, R. L'influence nationale et internationale des infrastructures de l'éducation comparée. In: HaLls, W.D. (Dir.). L'éducation comparée: questions et tendances contemporaines. Paris: UNESCO, 1990.

CRAMER, J.F.; BROWNE, G.S. Contemporary education: a comparative study of national systems. New York: Harcourt, Brace \& World, 1956.

CROSSLEY, M. Collaborative research, ethnography and comparative and international education in the South Pacific. International Journal of Education Development, 10, 1, 1990. p. 37-46.

CROSSLEY, M. Reconceptualising comparative and international education. Compare, 29, 3, 1999. p. 249-267.

CROSSLEY, M.; WATSON K. Case-study research methods and comparative education. Comparative Education, 20, 2, 1984. p. 193-207.

DEBEAUVAIS, M. Education comparée. In: Champy, P.; Etévé, C. (Dir.). Dictionnaire encyclopédique de l'éducation et de la formation. Paris: Nathan Université, 1994.

DEBEAUVAIS, M. L'influence des organisations internationales sur les politiques nationales d'éducation. In: Meuris, G.; De Cock, G. (Ed.). Education comparée. Essai de bilan et projets d'avenir. Bruxelles: De Boeck Université, 1997. p. 97-106.

DURKHEIM, E. Les règles de la méthode sociologique. Paris: PUF, 1895; 1986.

FABIAN, J. Time and the other. How anthropology makes its object. New York: Columbia University Press, 1983. 
FEATHERSTONE M. Global culture. Nationalism, globalization and modernity. London: Sage Publications, 1990.

GERTH K. (Dir.). Vers une Eurorégion de l'éducation. Actes du colloque "Les premières Eurorégionales de l'éducation", ARPEI, Editions PubliNord, 1994.

GIDDENS, A. Nation-State and violence. Cambridge: Polity Press, 1985.

GIDDENS, A. Les conséquences de la modernité. Paris: L'Harmattan, 1990; 1994.

GINSBURG, M. (Ed.). Understanding educational reform in global context. Economy, ideology and the State. New York \& London: Garland Publishing, 1991.

GLENN, C.L. The myth of the common school. Amherst: University of Massachusetts Press, 1988.

GREEN, A. Education, globalization and the Nation-State. London: McMillan, 1997.

GROSVENOR, I.; LAWN, M.; ROUSMANIERE, K. (Ed.). Silences \& images. The social history of the classroom. New York: Peter Lang, 1999.

GROUX, D.; PAUL, J.-J. L'éducation comparée en France: état des lieux. In: LECLERC, J.-M. (Dir.). L'éducation comparée: mondialisation et spécificités francophones. Paris: CNDP, 1999. p. 107-125.

GROUX, D.; TUTIAUX-GUILLON, N. (Dir.). Les echanges internationaux et la comparaison en éducation. Paris: L'Harmattan, 2000.

GRUBB, W.N. The convergence of educational systems and the role of vocationalism. Comparative Education Review, 29, 4, 1985. p. 526-548.

GRÜBER, K.H. Usages et mésusages des approches comparatives dans un cadre scientifique. In: Sirota, R. (Dir.). Autour du comparatisme en éducation. Paris: PUF, 2001. p. 95-107.

HALLS, W.D. L'éducation comparée: questions et tendances contemporaines. Paris: UNESCO, 1990.

HANS, N. Comparative education. London: Routledge, 1949. 
Do Estado-nação ao espaço-mundo...

HEYMAN, R. Comparative education from an ethnomethodological perspective. Comparative Education, 15, 2, p. 241-249, 1979.

HOFFMAN, D.M. Culture and comparative education: toward decentering and recentering the discourse. Comparative Education Review, 43, 4, 1999. p. 464-488.

HOLMES, B. The problem approach in comparative education: some methodological considerations. Comparative Education Review, 2, 1958. p. 1-23.

HOLMES, B. Problems in education. A comparative approach. London: Routledge \& Kegan Paul, 1965.

HOLMES, B. Comparative education: some considerations of method. London: Unwin Education Books, 1981.

HOLMES, B. L'éducation comparée en Europe occidentale. In: HaLls, W.D. L'éducation comparée: questions et tendances contemporaines. Paris: UNESCO, 1990.

HOROWITZ, I.L. The three worlds of development. New York: Oxford University Press, 1972.

HUNTER, I. Rethinking the school: subjectivity, bureaucracy and theory. New York: St Martin's Press, 1994.

JARVIS, P. Globalisation, citizenship and the education of adults in contemporary European society. Compare, 32, 1, p. 5-19, 2002.

JONES, B.; KEATING, M. (Ed.). The European Union and the regions. Oxford: Oxford University Press, 1995.

JULLIEN DE PARIS, M.-A. Esquisse d'un ouvrage sur l'éducation comparée et séries de questions sur l'éducation. Genève: Bureau International de l'Education, 1962 (réimpression de l'édition de 1817).

KALLEN, D. Les organisations internationales de l'éducation comparée. In: Leclerce, J.-M. (Dir.). L'éducation comparée: mondialisation et spécificités francophones. Paris: CNDP, 1999. p. 233-248.

KANDEL, I.L. Essays in comparative education. New York: Teachers' College, Columbia University, 1930. 
KANDEL, I.L. Studies in comparative education. London: Harrap, 1933. KASTORYANO, R. (Dir.). Quelle identité pour l'Europe? Le multiculturalisme à l'épreuve. Paris: Presses de Sciences Po, 1998.

KIENITZ, K. On the Marxist approach to comparative education in German Democratic Republic. Comparative Education Review, 7, 1, 1971. p. 21-31.

KING, E.J. Comparative studies and educational decision. London: Methuen, 1968.

LECLERCQ, J.-M. Intuitions et comparaisons. Revue Internationale d'Education, 1, Sèvres: Centre International d'Etudes Pédagogiques, 1994.

LECLERCQ, J.-M. (Dir.). L'éducation comparée: mondialisation et spécificités francophones. Paris: CNDP, 1999.

LÊ THÀN KHOI. L'éducation comparée. Paris: Armand Colin, 1981.

LE THÀN KHOI. Toward a general theory of education. Comparative Education Review, 30, 1, 1986. p. 12-29.

LÊ THÀN KHOI. Education et civilisations. Genèse du monde contemporain. Paris: UNESCO, 2001.

LUHMAN, N. Social systems. Stanford, CA: Stanford University Press, $1984 ; 1995$.

LYOTARD, J.-F. La condition post-moderne. Paris: Minuit, 1979.

MALLINSON, V. An introduction to the study of comparative education. London: Heinneman, 1957.

MASEMANN, V. Critical ethnography in the study of comparative education. Comparative Education Review, 26, 1, 1982. p. 1-15.

MASEMANN, V.; WELCH, A. (Ed.). Tradition, modernity and postmodernity in comparative education. International Review of Education, 43, $5 \& 6,1997$.

MAURICE, M. Méthode comparative et analyse sociétale. Les implications théoriques des comparaisons internationales. Sociologie $d u$ travail, 2, 1989. p. 175-192. 
Do Estado-nação ao espaço-mundo...

MEURIS, G.; DE COCK, G. (Ed.). Education comparée. Essai de bilan et projets d'avenir. Bruxelles: De Boeck Université, 1997.

MILWARD, S. The European rescue of the Nation-State. Berkeley: University of California Press, 1992.

MÜLLER, D.K.; RINGER, F.; SIMON, B. (Ed.). The rise of the modern educational system. Cambridge: Cambridge University Press, 1987.

NOAH, H.J.; ECKSTEIN, M. Towards a science of comparative education. New York: McMillan, 1969.

NOAH, H.J. The uses and abuse of comparative education. Comparative Education Review, 28, 4, 1984. p. 153-165.

NÓVOA, A. Modèles d'analyse en éducation comparée: le champ et la carte. Les Sciences de l'éducation pour l'ère nouvelle, 2-3, 1995.

NÓVOA, A. Histoire et comparaison. Essais sur l'éducation. Lisbonne: Educa, 1998.

NÓVOA, A. L'éducation comparée et les politiques éducatives dans l'espace européen. In: O’Dowd, M.; FäGERLInd, I. (Ed.). Mapping European comparative education research perspectives. Stockholm: Stockholm University \& The Prestige TMr Network, 2000. p. 201-224.

NÓVOA, A. Texts, images and memories. Writing "new" histories of education. In: Popkewitz, T.S.; Franklin, B.M.; Pereyra, M.A. (Ed.). Cultural history and education. Critical essays on knowledge and schooling. New York and London: Routledge Falmer, 2001. p. 45-66.

NÓVOA, A. Ways of thinking about education in Europe. In: NóvOA, A.; LaWn, M. (Ed.). Educating in a European space. London: Kluwer, 2002.

NÓVOA, A.; LAWN, M. (Ed.). Educating in a European space. London: Kluwer, 2002 (L'Harmattan, à paraître, 2003).

O’DOWD, M.; FÄGERLIND, I. (Ed.). Mapping European comparative education research perspectives. Stockholm: Stockholm University \& The Prestige TMR Network, 2000.

PAUL, J.J.; TOMAMICHEL, S. (Ed.). Le rôle des pouvoirs publics dans l'éducation. Approches comparatives des évolutions et tendances contemporaines. AFEC, Université Lumière - Lyon 2, 1996. 
PAULSTON, R.G. Mapping discourse in comparative education. Compare, 23, 2, 1993. p. 101-114.

PAULSTON, R.G. Social cartography. Mapping ways of seeing social and educational change. New York: Garland, 1996.

PEREYRA, M. La construcción de la educación comparada como disciplina académica. In: Schriewer, J.; Pedró, F. (Ed.). Manual de educación comparada. Barcelona: PPU, 1993. p. 255-323.

POPKEWITZ, T.S. The formation of school subjects. London: Falmer, 1987.

POPKEWITZ, T.S. (Ed.). Educational knowledge. Changing relationships between the State, civil society, and the educational communauty. New York: State University of New York Press, 2000.

POPKEWITZ, T.S. The production of reason and power. In: POPKEWITZ, T.S.; Franklin, B.M.; Pereyra, M.A. (Ed.). Cultural history and education. Critical essays on knowledge and schooling. New York and London: Routledge Falmer, 2001.

POPKEWITZ, T.S.; FRANKLIN, B.M.; PEREYRA, M.A. (Ed.). Cultural history and education. Critical essays on knowledge and schooling. New York and London: Routledge Falmer, 2001.

PZEWORSKI, A. Method of cross-national research, 1970-1983: an overview. In: Dierkes, M.; Weiler, H.N.; Antal, A.B. (Ed.). Comparative policy research. Aldershot: Gower, 1987.

PSACHAROPOULOS, G.; WOODHALL, M. (Ed.). Education for development. An analysis of investment choice. Oxford: Oxford University Press, 1985.

PSACHAROPOULOS, G. Comparative education: from theory to practice, or are you A:/neo.* or B:/* ist? Comparative Education Review, 34, 3, 1990. p. 369-380.

RAMIREZ F.O.; BOLI, J. The political construction of mass schooling: European origins and worldwide institutionalization. Sociology of Education, 60, 1987. p. 2-17.

RENAN, E. Qu'est-ce qu'une nation? In: Recueil de textes politiques. Paris: Presses Pocket, 1993. 
Do Estado-nação ao espaço-mundo...

RICOEUR, P. Du texte à l'action. Essai d'herméneutique II. Paris: Points Essais, 1986.

RICOEUR, P. Histoire et rhétorique. Diogène, 168, 1994. p. 9-26.

RINGER, F.K. Education and society in modern Europe. Bloomington \& London: Indiana University Press, 1979.

ROBERTSON, R. Glocalisation. In: Featherstone, M.; Lash, S.; Robertson, R. (Ed.). Global modernities. London: Sage, 1995.

ROSE, N. Powers of freedom. Cambridge: Cambridge University Press, 1999.

RUST, V.D.; SOUMARÉ, A.; PESCADOR, O.; SHIBUYA, M. Research strategies in comparative education. Comparative Education Review, 43, 1999. p. 108-109.

SADLER, M. How far can we learn anything of practical value from the study of foreign systems of education. In: Higginson, J.H. Selections from Michael Sadler. Liverpool: International Publishers Ltd., 1979 (original edition: 1900).

SANDIFORD, P. (Ed.). Comparative education. London and Toronto: Dent \& Sons, 1918.

SCARDILI, V. L'Europe de la diversité: la dynamique des identités régionales. Paris: Editions du CNRS, 1993.

SCHNAPPER, D. La communauté des citoyens. Sur l'idée moderne de nation. Paris: Gallimard, 1994.

SCHRIEWER, J.; KEINER, E. Communication patterns and intellectual traditions in eduational sciences: France and Germany. Comparative Education Review, 36, 1, 1992. p. 25-51.

SCHRIEWER, J. Système mondial et réseaux d'interrelation. L'intertionalisation de la pédagogie, un problème des sciences comparées de l'éducation. In: Meuris, G.; De Cock, G. Education comparée. Essai de bilan et projets d'avenir. Bruxelles: De Boeck Université, 1997a. p. 107-140.

SCHRIEWER, J. L'éducation comparée: mise en perspective historique d'un champ de recherche. Revue Française de Pédagogie, 121, 1997b. p. 9-28. 
SCHRIEWER, J. Coping with complexity in comparative methodology: issues of social causation and processes of macro-historical globalisation. In: Alexander, R.; Broadfoot, P.; Philips, D. (Ed.). Learning from comparing. New directions in comparative educational research. Vol. 1. Wallingford: Symposium Books, 1999. p. 33-72.

SCHRIEWER, J. Discourse formation in comparative education. Frankfurt: Peter Lang, 2000.

SCHRIEWER, J.; ORIVEL, F.; SWING, E.S. European educational systems: the framework of tradition, systemic expansion, and challenges for restructuring. In: Swing, E.S.; Schriewer, J.; Orivel, F. (Ed.). Problems and prospects in European education. Wesport, Connecticut \& London: Praeger, 2000. p. 1-20.

SCHULZE, H. Etat et nation dans l'histoire de l'Europe. Paris: Seuil, 1996. SIROTA, R. (Dir.). Autour du comparatisme en éducation. Paris: PUF, 2001. SLAMA, A.-G. L'angélisme exterminateur. Paris: Grasset, 1993.

STRAUSS, C. Partly fragmented, partly integrated. An anthropological examination of "postmodern fragmented subjects". Cultural Anthropology, 12, 3, 1997. p. 362-404.

SUTHERLAND, M.B. Communication and comparative education: the use of comparative journals. In: SMAWFIELD, D. (Ed.). International academic interchange and cooperation in higher education. Hull: British Comparative and International Educational Society, 1985.

SWING, E.S.; SCHRIEWER, J.; ORIVEL, F. (Ed.). Problems and prospects in European education. Wesport, Connecticut \& London: Praeger, 2000 .

TOBIN, J. Method and meaning in comparative classroom ethnography. In: Alexander, R.; Broadfoot, P.; Philips, D. (Ed.). Learning from comparing. New directions in comparative educational research. Vol. 1. Wallingford: Symposium Books, 1999. p. 113-134.

ULICH, R. The education of nations. A comparison in historical perspective. Cambridge, MA: Harvard University Press, 1961.

VALADIER, P. L'anarchie des valeurs. Paris: Albin Michel, 1997. 
Do Estado-nação ao espaço-mundo...

WALLERSTEIN, I. The modern world system. New York: Academic Press, 1974.

WALLERSTEIN, I. Unthinking social science. The limits of nineteencentury paradigms. Cambridge: Polity Press, 1991.

WATSON, K. Memories, models and mapping: the impact of geopolitical changes on comparative studies in education. Comparative Education Review, Compare, 28, 1, p. 5-31, 1998.

WATSON, K. Comparative educational research: the need for reconceptualisation and fresh insights. Compare, 29, 3, p. 233-247, 1999.

WEILER, H. Educational planning and social change: a critical review of concepts and practice. In: Altbach, P.G.; Arnove, R.; Kelly, G. (Ed.). Comparative education. New York: McMillan Publishing Company, 1982. p. 105-119.

WELCH, A.R. The functionalist tradition and comparative education. Comparative Education, 21, 1, 1985. p. 5-19.

WELCH, A.R. Class, culture and the State in comparative education: problems, perspectives and prospects. Comparative Education, 29, 1, 1993. p. 7-27. 